\title{
Thrombotic microangiopathy and fibrinolysis after hump-nosed viper envenomation
}

\author{
H Karunatilake ${ }^{1}$, T Nayakarathna $^{1}$, S Atapattu ${ }^{1}$, T Saparamadu $^{1}$, S Dharmasena ${ }^{1}$ \\ Ceylon Medical Journal 2012; 57: 45-46
}

\section{Introduction}

Snake envenomation and resultant clinical syndromes fascinate clinicians as they tend to have varied presentations and we do not yet fully understand their pathophysiology. We describe a patient who developed thrombotic microangiopathy (TMA) and isolated fibrinolysis following a hump-nosed viper (Hypnale sp.) bite. Difference between the venom induced consumptive coagulopathy (VICC) and the disseminated intravascular coagulation (DIC) is discussed to understand the resultant coagulopathy from this envenomation.

\section{Case report}

A 35-year old man who was bitten on his right leg by a hump-nosed viper presented two hours after the bite. Patient brought the dead snake to the hospital and it was positively identified as a hump-nosed viper. Further species classification was not done. On arrival at the hospital he had local pain and there was mild oedema at the site of the bite but no bleeding. He had no evidence of systemic envenomation. His medical history was unremarkable. His vital signs were stable and whole blood clotting time (WBCT) was less than 20 minutes. His hemoglobin $(\mathrm{Hb})$ was $15 \mathrm{~g} / \mathrm{dL}$, platelets were $326,000 / \mu 1$ and serum creatinine was $79.5 \mu \mathrm{mol} / \mathrm{L}$. Prothrombin time (PT) and partial thromboplastin time with kaolin (PTTK) were normal. He was given intravenous normal saline to avoid dehydration. After thirty-six hours urine output became low and his creatinine rose to $671.8 \mu \mathrm{mol} / \mathrm{L}$. Oliguric acute renal failure

${ }^{1}$ District General Hospital, Polonnaruwa, Sri Lanka.

Correspondence: HK, e-mail: <sanyalharindra@yahoo.com>. Received 5 July and revised version accepted 29 September 2011. Competing interests: none declared. 
was diagnosed and he was dialysed via a femoral catheter. $\mathrm{His} \mathrm{Hb}$ and platelet count started to drop and he became icteric. His $\mathrm{Hb}$ was $7.3 \mathrm{~g} / \mathrm{dL}$ and platelets dropped to $15,000 / \mu 1$. Unconjugated bilirubin was $102.6 \mu \mathrm{mol} / \mathrm{L}$. His WBCT, PT and PTTK remained within normal limits. Lactate dehydrogenase was markedly elevated (9400 U/ L) and the D Dimer was greater than $2.4 \mathrm{mg} / \mathrm{L}$. Blood smear showed fragmented cells and schistocytes confirming microangiopathic haemolysis. He underwent two more cycles of dialysis. Then his family members decided to seek alternative form of treatment and patient left the hospital against medical advice.

\section{Discussion}

Hump-nosed viper (genus Hypnale, family Crotalinae) is a moderately venomous snake found in India and Sri Lanka. In a series involving 10 hospitals in Sri Lanka, hump-nosed viper bites accounted for $35 \%$ of snake bite admissions [1]. Most victims show local swelling, pain and bleeding. Haemorrhagic blisters are seen at the bite site and rarely have lead to amputations [1]. One series failed to report any systemic toxicity [2]. However, there are several reports of coagulopathy, thrombocytopenia and acute renal failure occurring in isolation and in combination after hump-nosed viper envenomation [3-5]. In a series of 302 cases of confirmed hump-nosed viper bites, $10 \%$ had developed acute renal failure and $39 \%$ had incoagulable blood (20mins WBCT) but data on platelet counts were not available [1].

The combination of acute renal failure, thrombocytopenia and microangiopathic haemolytic anaemia characterises thrombotic microangiopathy and in snake envenoming it usually occurs in association with VICC [6]. In our patient coagulopathy was confined to a raised D Dimer level suggesting hypofibrogenaemia. His WBCT, PT and PTTK remained within normal limits. Coagulopathy in snake envenomation depends on which point the coagulation cascade is activated by the procoagulant snake toxin. This is a major difference in VICC from where coagulation is activated by tissue factor/ factor VII pathway [6]. It is difficult to predict the type of coagulopathy from the envenomation as most snake venom contains a mixture of procoagulant toxins acting at different points of the coagulation cascade. Apart from basic clotting tests, few laboratory data are available on the coagulopathy of snake venom in clinical studies. Out of procoagulant toxins present in viper venom, Thrombin Like Enzyme (TLE) mainly causes hypofibrogenaemia [7]. Often this hypofibrogenaemia is associated with thrombocytopenia [8]. Considering our patient's elevated $\mathrm{D}$ dimer (hypofibrogenaemia) and thrombocytopenia it is safe to assume hump-nosed viper venom contains predominantly TLEs as procoagulant toxin.

Unlike in DIC, coagulopathy in VICC has a rapid onset and resolves within 24-48 hours. Despite the resolution of the VICC, thrombotic microangiopathy progresses. This suggests an involvement of a different toxin to procoagulant toxin initiating TMA [6]. In combination with renal failure this clinical picture is similar to haemolyticuremic syndrome which usually results from a toxin causing renal endothelial damage. It is possible that a toxin in venom is causing a similar endothelial damage initiating the thrombotic microangiopathy [9].

The treatment for hump-nosed envenomation is supportive to date as there is no effective antivenom. Acute renal failure is treated with dialysis and therapeutic transfusions as required. TMA has been treated with plasmapheresis. However, its role remains uncertain [9]. It is important to appreciate that the onset, progression and resolution of VICC differ from that of DIC because it helps to understand the clinical syndromes that result from snake envenomation.

\section{References}

1. Ariaratnam CA, Thuraisingam V, Kularatne SAM, et al. Frequent and potentially fatal envenoming by hump-nosed pit vipers (Hypnale hypnale and H. nepa) in Sri Lanka: lack of effective antivenom. Transactions of the Royal Society of Tropical Medicine and Hygiene 2008; 102: 1120-6.

2. Sellahewa KH, Kumararatne MP. Envenomation by the hump-nosed viper (Hypnale hypnale). American Journal of Tropical Medicine and Hygiene 1994; 51: 823-5.

3. Premawardena AP, Seneviratne SL, Gunatilake SB, De Silva HJ. Excessive fibrinolysis: the coagulopathy following Merrem's hump-nosed viper (Hypnale hypnale) bites. American Journal of Tropical Medicine and Hygiene 1998; 58: 821-3.

4. De Silva A, Wijekoon ASB, Jayasena L. Haemostatic dysfunction and acute renal failure following envenoming by Merrem's hump-nosed viper (Hypnale hypnale) in Sri Lanka: the first authenticated case. Transactions of the Royal Society of Tropical Medicine and Hygiene 1994; 88: 209-12.

5. Premawardena A, Seneviratne SL, Jayanthi S, Gunathilake $\mathrm{SB}$, de Silva HJ. Coagulopathy and fibrinolysis following the bite of a hump-nosed viper (Hypnale hypnale). Transactions of the Royal Society of Tropical Medicine and Hygiene 1996; 90: 293.

6. Isbister GK. Snakebite doesn't cause disseminated intravascular coagulation: coagulopathy and thrombotic microangiopathy in snake envenoming. Seminars in Thrombosis and Hemostasis 2010; 36: 444-51.

7. Schneemann M, Cathomas R, Laidlaw ST, et al. Lifethreatening envenoming by the Saharan horned viper (Cerastes cerastes) causing micro-angiopathic haemolysis, coagulopathy and acute renal failure: clinical cases and review. Quarterly Journal of Medicine 2004; 97: 717-27.

8. Isbister GK. Procoagulant snake toxins: laboratory studies, diagnosis, and understanding snake bite coagulopathy. Seminars in Thrombosis and Hemostasis 2009; 35: 93-103.

9. Isbister GK, Little M, Cull G, et al. Thrombotic microangiopathy from Australian brown snake (Pseudonaja) envenoming. Internal Medicine Journal 2007; 37: 523-8. 